\title{
RESEARCH
}

Open Access

\section{Evaluating teen driving knowledge and behaviors following educational outreach}

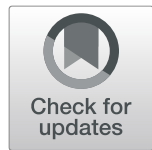

Kathy Monroe ${ }^{1,2^{*}}$, Michele Nichols ${ }^{1}$, Marie $\mathrm{Crew}^{2}$, Leslie Brown ${ }^{2}$ and William King ${ }^{2}$

From 24th Annual Injury Free Coalition for Kids Conference: Forging New Frontiers: Motor Vehicle Safety for All Ages

Fort Lauderdale, FL, USA. 06-08 December 2019

\begin{abstract}
Background: Teen driving educational events are an effective strategy to increase adolescent drivers' awareness of safe driving practices. The objectives of this study were to evaluate changing rates of self-reported driving practices and knowledge of the state Graduated Driver Licensing laws (GDL) by teens over a nine-year period in a single state.
\end{abstract}

Methods: This was a prospective observational study of high school students ages 14 to 19 years old. Paper surveys were sent to the high schools participating in teen driving educational events $(9$ schools in 2009 and 4 schools in 2018). Students in those schools completed surveys prior to the events. Students completing the anonymous survey were invited to the event. Questions evaluated awareness of state GDL and safe and risky driving behaviors. Statistical comparisons of survey answers from 2009 to 2018 were analyzed using the $z$ test of proportions ( 2 tailed, alpha 0.05).

Results: A total of 397 students participated in 2018 with ages ranging from 14 to 19 years. Racial distribution was $81 \%$ white, $14 \%$ black, and there were $57 \%$ female participants. Only $69 \%(n=273)$ reported "always" wearing their seatbelt. When asked about high risk behaviors, 78\% $(n=309)$ of adolescents reported they personally "never" text while driving; $97 \%$ (385); never drive after drinking, and $87 \%(n=344)$ never ride with someone who has been drinking. Compared to 2009 participants (1304 students, 9 schools from central part of state), the students in 2018 (4 schools scattered across state) reported wearing seatbelts "always" ( $n=69 \%$ vs $39 \% ; p<0.001$ ); "never texting while driving" (78\% vs 33\%; $p<0.001$ ); and "never drinking and driving" (97\% vs $88 \% ; p<0.001$ ). No significant difference in rates of students having taken a driving education class nor driving over speed limit were reported.

Conclusion: Results are encouraging that participants in 2018 report more use of seatbelts, less texting while driving, less drinking while driving and lower numbers of being in MVC than in 2009. However, rates of high-risk driving behaviors are still concerning.

Keywords: Teen driving, Education, Risky behaviors

\footnotetext{
* Correspondence: kmonroe@peds.uab.edu

'Department of Pediatrics, Division of Pediatric Emergency Medicine,

University of Alabama Birmingham, Birmingham, AL, USA

${ }^{2}$ SafeKids of Alabama, Children's of Alabama, 1600 7th Ave So, Suite 110 CPP.

Birmingham, AL Al 35233, USA
} 


\section{Background}

Motor vehicle crashes (MVCs) are the number one cause of death for teens in the U.S. (Center for Disease Control and Prevention n.d.). The risk of motor vehicle crashes is higher among 16- to 19-year-olds than among any other age group. In fact, per mile driven, teen drivers 16 to 19-years old are three times more likely than drivers 20 years and older to be involved in a fatal crash. (Insurance Institute for Highway Safety (IIHS) 2010). Alabama, the state in which this study occurred, consistently ranks among the worst 10 states in the nation for teen driving fatalities (Teen driving safety 2019). Graduated Driver Licensing (GDL) laws were enacted in Alabama in 2002, with strengthening of those laws in 2010 and again in 2015. According to the state Department of Public Health, alcohol, non-seatbelt use, and distractions are the three primary contributing factors to teen driving deaths (Alabama Department of Public Health n.d.).

Inexperience and immaturity both contribute to high crash rates involving teen drivers (McKnight and McKnight 2000). Adolescent drivers tend to engage in numerous risky behaviors such as driving over the speed limit, which has been found to significantly correlate with a greater risk for crashes (Elander et al. 1993). They are more likely to engage in other risk-taking behaviors as well. According to 2004 National Highway Traffic Safety Administration (NHTSA) data, 17\% of young drivers 16-20 years old had a blood alcohol concentration at or above $0.08 \%$, the level at which all states define drunk driving (National Highway Traffic Safety Administration 2005). According to various NHTSA sponsored state and national safety belt surveys, youth 16-24 years old are observed wearing safety belts at rates $5-15 \%$ below rates for those older than 24 years (Williams et al. 2003; Glassbrenner 2003). Numerous surveys conducted in high school parking lots indicate typical teen belt use is about $50-60 \%$, depending upon the state and the school (McCartt and Shabanova 2002), but that rates of seat belt use among teens vary dramatically based on age, gender, race, and urban/rural setting and region of the country.

These findings suggest that not only are interventions to increase seat belt use by young people greatly needed, but also that targeted messages among teens-based on age, gender, race, and urban/rural and regional differences (Juarez et al. 2006). There has been acknowledgement that strategies targeting the general population do not necessarily have the same effect on all segments of the population (Juarez et al. 2006). Graduated Driver Licensing laws, driving instructional classes, parent teen driving contracts, and pediatrician counseling have all been suggested as means of influencing teen driving fatalities. We began hosting crash course teen driving events at high schools in our state in 2009 and have continued these events to present day. Since our state has high teen driving fatality rates, our objective in this study was to determine the prevalence of high risk driving behaviors (including non-use of seat belts, texting and drinking while driving) among area teens in 2018 and to evaluate changing rates of self-reported risky driving practices and knowledge of the state GDL by teens compared to those in 2009.

\section{Methods}

This was a prospective observational study of high school students ages 14 to 19 years old. We surveyed the students to assess knowledge of the Alabama GDL law and prevalence of high-risk driving behaviors in 2018 and compared those to the original responses from 2009. This study utilized a teen driver questionnaire to provide estimates and baseline information on teen driving behaviors in our state (Table 1). The questionnaire was adapted from the Centers for Disease Control and Prevention (CDC's) National Youth Risk Behavioral Survey (NYRBS) (Eaton et al. 2012). Questions regarding behavior as drivers and passengers in the car were included verbatim. In addition, questions were included to determine if the students had discussed safe driving with either parents or with their primary care physician. The added questions were written in similar style to the NYRBS questions and were pilot tested with a small group of adolescents for readability. The completion of a driver education course was also documented by selfreport from the participants. Our survey also included questions about the Alabama GDL law including. Institutional Review Board approval was obtained.

We began hosting crash course teen driving events at 9 high schools in the central part of Alabama 2009. With the 2009 driving event, paper surveys were distributed prior to the teen driving educational event to evaluate self-reported driving behaviors and knowledge of GDL from the high school students. The educational event following the surveys was a 1 day event in which a variety of speakers addressed the students including a state trooper, a mother of a child who died in a motor vehicle crash, and a young adult who survived a motor vehicle crash, but is paralyzed from the crash. There were interactive sessions including driver's simulation, drunk goggle demonstrations, and a jeopardy-style game about GDL awareness.

For this current study, paper surveys were sent to four high schools participating in the teen driving educational events scattered throughout Alabama. Inclusion criteria were students ages 14 years and older in one of the participating schools. A letter was sent to students' parents informing them of the survey and allowing them to have their child opt out of participation if they so desired. 
Table 1 Teen Driving Survey Questions

\section{Survey Questions}

1. How old are you?

A. 14 years old or younger D. 17 years old

B. 15 years old E. 18 years old or older

C. 16 years old

2. What is your sex?

A. FemaleB. Male

3. What is your race? (Select one or more responses.)

A. American Indian or Alaska NativeD. Native Hawaiian or Other Pacific Islander

B. Asian E. White

C. Black or African American F. Hispanic or Latino

4. Has your doctor talked to you and/or your parents about: (select all that apply)

_ wearing seatbelts _ dangers of drinking and driving

_ dangers of texting while driving dangers of drug use with driving

you

speeding__ number of passengers that should ride in car with

driving contract __ haven't seen my doctor in the past 3 yrs.

none of these

5. How often do you wear a seat belt when riding in a car?

A. Never

B. Rarely

C. Sometimes

D. Most of the time

E. Always

6. What are reasons why you don't always wear your seatbelt?

_ don't think they work _ afraid if I have an accident I'll be stuck

_ don't have one_forget to put it on

_ just don't want to__ it messes up my clothes

_ none of my friends do__ I always wear one

7. How often in the past 30 days, have you observed your parents text while driving?

A. Never

B. Rarely

C. Sometimes

D. Most of the time

E. Always

8. How often do your parents wear a seatbelt?

A. Never

B. Rarely

C. Sometimes

D. Most of the time

E. Always

9. During the past 30 days, how many times did you ride in a car or other vehicle driven by someone who had been drinking alcohol? A. 0 times

B. 1 time

C. 2 or 3 times

D. 4 or 5 times

E. 6 or more times

10. During the past 30 days, how many times did you drive a car or other vehicle when you had been drinking alcohol?

A. 0 times

B. 1 time

C. 2 or 3 times

D. 4 or 5 times

E. 6 or more times

F. I do not drive/have a permit or license

11. During the past 30 days how many times did you ride in a care or other vehicle driven by someone who was texting while driving? A. 0 times

B. 1 time
Table 1 Teen Driving Survey Questions (Continued)

Survey Questions

C. 2 or 3 times

D. 4 or 5 times

E. 6 or more times

12. During the past 30 days how many times did you drive a car or other vehicle while texting?

A. 0 times

B. 1 time

C. 2 or 3 times

D. 4 or 5 times

E 6 or more times

F. I do not drive/have a permit or license

13. How long after you obtained your license were you allowed to drive with friends in the car?

A. ImmediatelyB. DaysC. WeeksD. MonthsE. Years

F. I do not drive/have a permit or license

14. How much time have you spent discussing the dangers of driving with your parents?

A. noneB. $<1$ h C.1-3 h D. 4-6h E. $>6$ h

15. Have you ever taken a driving class? YesNo

If yes, was it a class at your school?

Was it a class at another site?

16. Have you ever been involved in a car crash as a driver? A. Yes b. No c. Do not drive

17. Which of the following have you discussed with your parents? (select all that apply)

_ wearing seatbelts _ dangers of drinking and driving

__ dangers of texting while driving __ dangers of drug use while driving

_speeding__ number of passengers that teen can have

_rules when friends are in car___ driving contract

none of these

18. Do you routinely drive 5-10 miles over the speed limit? A.Yes B. No C. Do not drive

19. In the past thirty days, have you driven while under the influence of drugs?

A. YesB. NoC. Do not drive

20. Are you aware of the graduated driver's license laws?Yes No

21. Do you ever use your cellphone (for any reason) while driving?

A. YesB. NoC. Don't have a cell phoneD. Don't drive yet

22. If yes, what could influence you to give up your cell phone while driving (or what might influence you when you begin driving to not use cell phone)?

(check all that apply)

if your license could be taken away if caught if friends gave up their phone

if there was a law against using phone could get insurance discount

if parents knew every time you used phone convince me to stop using my cell phone

don't use cell phone while driving

23. Have you ever signed a driver safety contract?

A. YesB. NoC. Never heard of one

If no, would you be interested in one

24. If you are aware of the teen driving contracts but haven't signed one, why not?

A. I don't drive yet

B. No one has ever asked me to sign a contract

C. I refused

25. If you have signed a driver safety contract, did you sign contract: a. After my parents found out I was speeding 
Table 1 Teen Driving Survey Questions (Continued)

Survey Questions
b. After I had a car crash
c. After my parents found out I had driven after drinking
d. After my parents found out I had driven while texting
e. Before I started driving
f. None of the above
g. I have not signed a driving contract
26. According to Alabama Law, what is the curfew hour for teen drivers
under the graduated drivers license rules:
a. 8 pm b. 9 pm c. 10 pm d. 11 pm 3.12 am

The surveys were then sent to the participating schools and the questionnaire was distributed to high school students for completion prior to the educational event. Students completing the survey were invited to the event, but since the survey was anonymous, it is possible some students completed survey, but did not attend event. Participation in the survey was voluntary. Consent for the survey was by completion and return of survey (opt out method). Consent for event was written consent by parents to the school to allow them to travel to the event. Respondent identities were concealed as all surveys were anonymous. There was no individual incentive to participate. In 2009 there was a $\$ 500$ award to the school with the most surveys.

In 2009 there were nine schools from the central portion of the state participating in one event. In 2018 there were four schools from across the state (none in the central portion that participated in 2009) participating in four separate events. We calculated descriptive statistics and compared survey answers from 2009 to 2018 using the $\mathrm{z}$ test of proportions using a 2 tailed alpha level of 0.05 as significant. All analyses were conducted in Epi Info 7.0.9.7 (2/9/2012, CDC, Atlanta Georgia, 2011).

\section{Results}

A total of 397 students from four schools across Alabama participated in 2018. Ages of students ranged from 14 years $(n=44) ; 15$ years $(n=171) ; 16$ years $(n=101) ; 17$ years $(n=67)$, and 18 or older $(n=13)$, with $57 \%$ female $(n=228)$. Racial distribution was white $(n=323 ; 81 \%)$; black $(n=56 ; 14 \%)$; and Hispanic $(n=12 ; 3 \%)$. Only $69 \%$ $(n=273)$ reported "always" wearing their seatbelt, and when asked if any physician had ever talked to the adolescent about wearing seat belts only 168 (42\%) said yes. Only $63 \%(n=249)$ reported having taken a driving class in the past. A total of $55 \%(n=218)$ reported routinely going more than 10 miles above speed limit.

When asked about high risk behaviors, 78\% $(n=309)$ of adolescents reported they personally "never" text while driving, 97\% $(n=385)$ participants stated they never drive after drinking, and $87 \%(n=344)$ stated they never "ride with someone whose been drinking." Students $(n=225)$, reported seeing their parents wear seatbelts "always" $64 \%$ of time. When asked if their parents text while driving, only $26 \%$ said "never" and $15 \%$ said "most or all the time." When asked if their parents had ever discussed safe driving with them, $15 \%$ reported no time was spent; $41 \%<1 \mathrm{~h}, 27 \% 1-3 \mathrm{~h}, 8 \%$ said $4-6 \mathrm{~h}$, and $9 \%$ over $6 \mathrm{~h}$. A total of 230 (58\%) were aware of the GDL laws, with only $26 \%$ correctly answering the curfew question.

In 2009, there was one teen driving educational event with nine schools participating from one county in central portion of the state. There were 1304 respondents to the survey in 2009. These schools did not overlap with the four schools participating in 2018. Comparing to 2009 participants, the students in 2018 reported wearing seatbelt "always" ( $n=69 \%$ vs $39 \% ; p<0.001)$; "never texting while driving" ( $78 \%$ vs $33 \%$; $\mathrm{p}<0.001)$; and "never drinking and driving" (97\% vs $88 \% ; p<0.001$ ) (see Table 2). No significant difference in rates of having taken a driving class nor driving over speed limit was demonstrated between the 2 years.

\section{Discussion}

This study gives insight into current teen driving behaviors in one state, and how those compare to selfreported teen driving behaviors from 10 years ago. The students in 2018 reported higher rates of "always wearing a seatbelt," "never texting while driving," and "never drinking and driving" compared to the students in 2009. Motor vehicle crashes remain the leading cause of teen deaths despite preventive efforts (Missikpode et al. 2018). The need for innovative behavioral interventions for teen drivers has been made clear, and previous

Table 2 Comparison of Participant Responses from 2018 compared to Responses in 2009

\begin{tabular}{|c|c|c|c|c|}
\hline Question & 2009 & 2018 & \multirow{2}{*}{$\begin{array}{l}Z \\
\text { score }\end{array}$} & \multirow[t]{2}{*}{$\overline{p \text {-value }}$} \\
\hline$N=$ & 1304 & 397 & & \\
\hline In the past 30 days have you "Always" worn a seatbelt when driving? & $504(39 \%)$ & $273(69 \%)$ & 8.3 & $<0.001$ \\
\hline In the past 30 days how often have you text while driving (NEVER) & $441(33 \%)$ & $309(78 \%)$ & 8.9 & $<0.001$ \\
\hline In the past 30 days how often have you driven after drinking alcohol? (NEVER) & $1146(88 \%)$ & $385(97 \%)$ & 4.5 & $<0.001$ \\
\hline Have you ever taken a driving class & $765(59 \%)$ & $249(63 \%)$ & -1.5 & 0.14 \\
\hline In the past 30 days have you routinely driven $5-10$ miles over the speed limit? & 764 (59\%) & $218(55 \%)$ & -0.12 & 0.9 \\
\hline
\end{tabular}


studies have shown benefit from school based programs (Unni et al. n.d.; Hafner et al. 2019). Local surveillance is important in guiding interventions and the NYRBSS is an important tool in gaining insight into teen drivers' beliefs and behaviors. Our events combined surveillance of behaviors with school based educational outreach.

Results from our surveillance study were encouraging in that participants in 2018 report more use of seatbelts, yet only $69 \%$ report always using seatbelts, so more work needed. Of the teens (13-20 years old) who died in passenger vehicle crashes in 2013 approximately 56\% were not wearing a seat belt at the time of the crash (National Highway Traffic Safety Administration n.d.). Research shows seat belts reduce serious crash-related injuries and deaths by about half, (Kahane 2013) yet compared with other age groups, teens have the lowest rate of seat belt use. In 2013, only 55\% of high school students reported they always wear seat belts when riding with someone else (Centers for Disease Control and Prevention 2013). Our state has had a primary seatbelt law since 1991, yet we continue to see many teens who do not routinely wear their seat belt with $31 \%$ of our survey respondents reporting inconsistent seat belt usage. The fine for not wearing a seatbelt in our state is only twenty-five dollars.

Cell phones have received much attention as a source of driver distraction. Our state has had a texting ban in effect since 2012, and the Graduated Driver Licensing law specifically bans any handheld device for teen drivers (Beck et al. 2002). Despite this legislation, 31\% of survey respondents reported texting while driving in the past month in 2018 survey. There was a significant improvement; however, with $78 \%$ reporting never texting while driving in 2018 compared to 2009 when only 33\% said they never text while driving.

At all levels of blood alcohol concentration (BAC), the risk of involvement in a motor vehicle crash is greater for teens than for older drivers (Ginsburg et al. 2009). In a national survey conducted in 2013, $22 \%$ of teens reported that, within the previous month, they had ridden with a driver who had been drinking alcohol (Centers for Disease Control and Prevention n.d.). Among students who drove, $10 \%$ reported having driven after drinking alcohol within the same one-month period (Centers for Disease Control and Prevention n.d.). In our study, the reported rates of "never" drinking and driving had improved from 88 to $97 \%$ of respondents in 2009 to 2018 respectively. Unfortunately, we found no change in those reporting routinely driving over the speed limit, with over $50 \%$ of respondents reporting routinely driving more than 10 miles over the speed limit in both groups.

The results of our study reveal an alarming number of risky behaviors in teen drivers. The National Young Risk
Behavior Survey questioned 9th, 10th and 11th graders $(14,15$ and 16 years old). While our participants were primarily 15 and 16 years old, we also surveyed 17 and 18-year olds. Although not a direct comparison due to the slight age differences, our numbers were comparable to the 2011 NYRBS. Nationwide, $7.7 \%$ of students rarely or never wear a seatbelt, $8.2 \%$ drove in the last 3 days after consuming alcohol, and $32.8 \%$ texted while driving in the last 30 days (McKnight and McKnight 2000). Our local respondents reported 18,1 , and $31 \%$ respectively. It is clear our teen drivers are participating in risky driving behaviors at an alarming rate, even when compared to national data.

Despite the presence of a GDL law in our state since 2002 with revisions in 2010 and 2015, our survey indicates many teens do not follow the guidelines of this law. Besides the GDL, our state has had a primary seat belt law since 1997, yet only $69 \%$ of respondents said they always wear their seatbelt when driving. In addition, $55 \%$ of respondents reported they routinely drive 5-10 $\mathrm{mph}$ over the speed limit. It is apparent that legislation is important, but there are additional factors involved in teen driving safety.

\section{Limitations}

One limitation of any self-reported survey is the risk of responder bias. As a result, participants may not answer truthfully, but this survey was anonymous and voluntary, so participants had no reason to falsify answers. There may also be bias in the type of student who would complete this kind of survey. We also did not specifically ask if the student respondent was a driver, thus we were not able to further analyze the responses by driver status. There is also the potential for recall bias as this survey asks respondents to remember the frequency of certain behaviors and actions. However, the survey questions were either taken directly from the NYRBS or created in similar style, and the NYRBS tool has been validated for reliability (Brenner et al. 1995). The environment for some risk driving behaviors (e.g. texting) are different in 2018 compared to 2009, so these results should be interpreted with some caution. This study was conducted in one southern state with a significant teen driving fatality rate; therefore, the results may not be generalizable to teenagers in other states. Also, the surveys were not distributed to all Alabama teenagers, and only represents the subset of students attending one of the high schools participating in the educational events. The schools who participated in 2018 were not the exact same schools that participated in 2009; however, the same survey for the same age population in the same state was utilized. Thus, we can only describe general differences in responses between the 2 years, but not 
specific changes between the same student or among the same schools.

\section{Conclusions and future directions}

Teen driving death and injury is a significant problem in our nation. Results are encouraging that participants in 2018 report more use of seatbelts, less texting while driving and less drinking while driving than in 2009. However, rates of seatbelt use are still only $69 \%$, and low rates of physicians discussing seatbelts were still reported. Also, an alarming number of teens still report risky driving behaviors in this study. Some state-based interventions such as the graduated driver licensing law, safe driving media campaigns, and a Teen Driving Toolkit for state pediatricians have already been instituted in Alabama, and the teen driving educational events have expanded to cover the different areas of the state. Persistent efforts to increase public awareness of teen driving safety issues is indicated.

\section{Abbreviations}

BAC: Blood alcohol concentration; CDC: Centers for Disease Control and Prevention; GDL: Graduated driver's license; MVC: Motor vehicle crash; NHTSA: National Highway Transportation Safety Administration; NYRBS: National youth risk behavior survey; U.S.: United States

\section{Acknowledgements}

Not applicable.

\section{About this supplement \\ This article has been published as part of Injury Epidemiology Volume 7 Supplement 1, 2020: Proceedings from the 24th Annual Injury Free Coalition for Kids ${ }^{\circledR}$ Conference: Forging New Frontiers: Motor Vehicle Safety for All Ages. The full contents of the supplement are available online at https:/injepijournal. biomedcentral.com/articles/supplements/volume-7-supplement-1.}

\section{Authors' contributions}

KM was involved in the design of the study, the IRB, the data collection and analysis and manuscript preparation. MN was involved in the design of the study, the data analysis and manuscript preparation. MC and LB were involved in the data collection and manuscript review BK was involved in the design of the study, the data analysis and the manuscript review. All authors have read and approved the final document.

\section{Funding}

The teen driving events were funded in 2009 by Allstate and in 2018 by State Farm. The study was conducted in conjunction with these events and was unfunded. Publication charges were funded by the Injury Free Coalition for Kids $s^{\oplus}$.

\section{Availability of data and materials}

The datasets used and/or analyzed during the current study are available from the corresponding author on reasonable request.

\section{Ethics approval and consent to participate}

This study was approved by the University of Alabama IRB and participation was anonymous and voluntary. Consent for the survey was by completion and return of survey (opt out method).

\section{Consent for publication}

Not applicable.

\section{Competing interests}

The authors have no competing interests or financial relationships relevant to this article to disclose.
Published: 12 June 2020

\section{References}

Alabama Department of Public Health. Teen driving facts and figures. Available at: http://www.alabama department of public health.gov/teendriving/factsand-figures.html. Accessed 21 July 2019.

Beck KH, Hartos J, Simons-Morton B. Teen driving risk: the promise of parental influence and public policy. Health Educ Behav. 2002;29:73-84.

Brenner N, Collins J, Kann L, Warren C, Williams B. Reliability of the youth risk behavior survey questionnaire. Am J Epidemiol. 1995;141(6):575-80.

Center for Disease Control and Prevention. "Web-based injury statistics query and reporting System (WISQARS)." Available at: http://www.cdc.gov/nchs/ products/databriefs/db37.htm\#fig2. Accessed 21 July 2019.

Centers for Disease Control and Prevention. Youth risk behavior surveillance system 2013 YRBS Data User's Guide. ftp://ftp.cdc.gov/pub/data/yrbs/2013/ YRBS_2013_National_User_Guide.pdf. Accessed 23 Feb 2017.

Centers for Disease Control and Prevention. Youth risk behavior surveillance system (YRBSS). http://www.cdc.gov/healthyyouth/data/yrbs/index. htm. Accessed 25 July 2016.

Eaton DK, et al. Youth risk behavior surveillance- United States, 2011. Morb Mortal Wkly Rep. 2012;61(4):1-168.

Elander J, West R, French D. Behavioral correlates of individual differences in road-traffic crash risk: an examination method and findings. Psychol Bull. 1993:113:279-94.

Ginsburg KR, Durbin DR, García-España JF, et al. Associations between parenting styles and teen driving, safety-related behaviors and attitudes. Pediatrics. 2009;124:1040-51.

Glassbrenner D. Safety Belt use in 2003 [cited 2004 Feb 5, 2004]; DOT HS 809 646. Washington, DC: National Highway Traffic Safety Administration, US Department of Transportation; 2003. Available at http://www-nrd.nhtsa.dot. gov/pdf/nrd-30/NCSA/Rpts/2003/809646.pdf. Accessed April 2006.

Hafner J, Bleess B, Famakinwa M, Wang H, Coleman M. The effect of a community crash reenactment program on teen alcohol awareness and behavior. Adol Health Med Therapeutics. 2019;10:83-90.

Insurance Institute for Highway Safety (IIHS). Fatality facts: teenagers 2010. Available at: http://www.iihs.org/topics/fatality-statistics/detail/teenager. Accessed 21 July 2019.

Juarez P, Schlundt D, Goldzweig I, Stinson N. The science of safe driving among adolescents. A conceptual framework for reducing risky teen driving behaviors among minority youth. Inj Prev. 2006;12(1):i49-55.

Kahane CJ. Injury vulnerability and effectiveness of occupant protection technologies for older occupants and women. http://www.nrp.nhtsa.dot.gov/ Pubs/811766.pdf. Published May 2013. Accessed 1 July 2016.

McCartt AT, Shabanova VI. Teenage Seat Belt Use: White Paper. 2002. Available at http://www.nsc.org/public/teen0702.pdf. Accessed April 2006.

McKnight AJ, McKnight AS. The behavioral contributors to highway crashes of youthful drivers. Annu Proc Assoc Adv Automot Med. 2000;44:321-33.

Missikpode C, Peek-Asa C, McGehee D, Torner J, Wakelands W, Wallace R. Teen driver system modeling: a tool for policy analysis. Inj Epidemiol. 2018;5(34):110.

National Highway Traffic Safety Administration. Traffic Safety Facts 2004 data. Washington, DC: US Department of Transportation; 2005. Available at http:// www-nrd.nhtsa.dot.gov/pdf/nrd-30/NCSA/TSF2004/809911.pdf. Accessed April 2006.

National Highway Traffic Safety Administration. Occupant protection. Found at http://www-nrd.nhtsa.dot.gov/Pubs/812153.pdf. Accessed February 20, 2017.

Teen driving safety 2019: least and most dangerous states. Available at: https:// www.carinsurance.com/articles/teen-drivig-safety-least-and-most-dangerousstates.aspx. Accessed 21 July 2019.

Unni P, Estrada C, Chung D, Riley E, Worsely-Hyand L, Stinson N. A multiyear assessment of a hospital-school program to promote teen motor vehicle safety. J Trauma Acute Care Surg. 2017;83(2):289-95.

Williams AF, McCartt AT, Geary L. Seatbelt use by high school students. Inj Prev. 2003;9:25-8.

\section{Publisher's Note}

Springer Nature remains neutral with regard to jurisdictional claims in published maps and institutional affiliations. 